\title{
Successful Treatment of Metastatic Anal Canal Adenocarcinoma with mFOLFOX6 + Bevacizumab
}

\author{
Mototsugu Matsunaga ${ }^{a} \quad K^{2}$ eisuke Miwa ${ }^{a}$ Yosuke Oka \\ Sachiko Nagasu ${ }^{a, b}$ Takahiko Sakaue ${ }^{a, c}$ Masaru Fukahori ${ }^{a, c}$ \\ Tomoyuki Ushijima ${ }^{a, c}$ Yoshito Akagi ${ }^{b}$ \\ ${ }^{a}$ Multidisciplinary Treatment Cancer Center, Kurume University Hospital, ${ }^{b}$ Department of \\ Surgery, Kurume University School of Medicine, and 'Division of Gastroenterology, \\ Department of Medicine, Kurume University School of Medicine, Fukuoka, Japan
}

\section{Key Words}

Anal canal adenocarcinoma · Abdominoperineal resection · Metastasis - mFOLFOX6 . Bevacizumab

\begin{abstract}
Anal canal adenocarcinoma is a relatively rare malignancy without established diagnostic and treatment criteria. Case reports of chemotherapy for anal canal adenocarcinoma with distant metastasis are limited, and there is no convincing evidence for treatment effectiveness. A 62year-old man complained of difficulty in defecation, anal pain, and bleeding during bowel movement. He was diagnosed with moderately differentiated primary anal canal adenocarcinoma. A computed tomography scan revealed multiple metastases in the lung and liver. The patient was treated with abdominoperineal resection to control local tumor growth and then with chemotherapy consisting of mFOLFOX6 + bevacizumab. Because he had an activating KRAS mutation, anti-EGFR therapy was not considered. A reduction in the size of lung and liver metastases was observed after 4 courses of mFOLFOX6 + bevacizumab, and after 22 courses, maximum reduction in the metastatic lesions was achieved. The patient demonstrated tolerable levels of oxaliplatin-related peripheral neurotoxicity (grades 1-2) and was considered as having partial response to treatment. He is currently at the partial response state for 1 year. We plan to continue the treatment unless the patient develops progressive disease or intolerable adverse reactions. This case demonstrates that anal canal adenocarcinoma with distant metastases could be successfully treated with mFOLFOX6 + bevacizumab therapy according to the guidelines for rectal carcinoma. However, as anal canal carcinoma
\end{abstract}

\section{KARGER}


Matsunaga et al.: Successful Treatment of Metastatic Anal Canal Adenocarcinoma with mFOLFOX6 + Bevacizumab

has multiple histological subtypes, it is important to establish subtype-specific treatment strategies.

(C) 2016 The Author(s)

Published by S. Karger AG, Basel

\section{Introduction}

Malignant tumors of the anus are uncommon and scarcely encountered in the field of proctology. Anal carcinomas are relatively rare, representing less than $2.5 \%$ of all gastrointestinal carcinomas [1]. According to the report of the Japanese Society for Cancer of the Colon and Rectum on the frequency of cancers, anal canal carcinomas accounted for only $0.8 \%$ of rectal carcinomas [2]. Despite the low incidence, treatment of anal canal carcinoma is very important because it significantly influences the quality of life of cancer patients. It has been reported that the incidence of anal canal adenocarcinomas is high in Japan, while that of squamous cell anal canal carcinomas is high in Western countries [3]. The standard therapy for anal adenocarcinoma has not yet been established in Japan or Western countries, and current guidelines recommend that patients with anal carcinoma should be treated similarly to those with rectal carcinoma [4, 5]. Here, we report a case of anal canal adenocarcinoma with distant metastases to the lung and liver successfully treated with mFOLFOX6 + bevacizumab according to the guidelines for rectal carcinoma.

\section{Case Presentation}

A 62-year-old man was admitted to a local clinic complaining of difficulty in defecation, anal pain, and bleeding during bowel movement for approximately 2 months. His past medical history and family history were unremarkable. The examination revealed an anal mass, and the patient was suspected to have anal canal carcinoma and was referred to our hospital for further testing and treatment. We found a solid mass of a thumb tip size with an uneven indented surface, which was erosive and bled easily; the mass was located mainly on the left side of the anal canal (fig. 1). Although the mass was protruding out of the anal area, no anal fistula or pagetoid spread was observed. After the biopsy, the mass was diagnosed as moderately differentiated adenocarcinoma. A computed tomography (CT) scan at the time of the first examination revealed multiple masses in the lung and liver. Gastrointestinal endoscopy showed no primary lesions other than the anal mass. The patient was diagnosed with anal canal adenocarcinoma with multiple metastases to the lung and liver. Although there were distant metastases, we decided to initiate treatment for the anal cancer immediately, because the patient was experiencing difficulty in defecation, pain, and bleeding due to the growing tumor. First, we performed abdominoperineal resection to control local growth of the tumor; then, the patient was referred for chemotherapy to treat the distant metastases. The patient's general condition was good, and there were no significant problems with bone marrow, liver, or renal functions. It is generally recommended that patients with anal canal adenocarcinoma should be treated similarly to those with rectal carcinoma $[4,5]$. The patient was treated according to the guidelines for rectal carcinoma with distant metastasis. After considering the toxicity profile, administration method, and the patient's compliance, we chose mFOLFOX6 (folinic acid, fluorouracil, oxaliplatin) + bevacizumab therapy. Because the patient had an activating G12D mutation in the KRAS proto-oncogene, anti-EGFR therapy was not considered. 
Matsunaga et al.: Successful Treatment of Metastatic Anal Canal Adenocarcinoma with mFOLFOX6 + Bevacizumab

Before the start of chemotherapy, thoracic-abdominal CT scan was performed, which showed multiple metastatic lesions in the lung and liver, similar to those revealed by the initial examination (fig. 2). A reduction in the size of the lung and liver metastases was observed already after 4 courses of mFOLFOX6 + bevacizumab therapy, and after 22 courses, CT scan showed maximum reduction in the metastatic lesions in both sites (fig. 3). Based on the chemotherapy results, the patient was classified as having a partial response. Thus, before the start of chemotherapy, serum levels of the tumor markers CEA and CA 19-9 were elevated $(38.1 \mathrm{ng} / \mathrm{ml}$ and $101.9 \mathrm{U} / \mathrm{ml}$, respectively), but gradually decreased with the reduction of the metastatic lesions (the lowest levels were $4.7 \mathrm{ng} / \mathrm{ml}$ and $24.6 \mathrm{U} / \mathrm{ml}$, respectively). At the time of this report, the patient was in the partial response state for 1 year. We plan to continue the current treatment unless the patient develops progressive disease or intolerable adverse reactions.

\section{Discussion}

The term anal canal carcinoma is applied to tumors located in the tubular body of the anal canal from the upper margin of the puborectalis muscle to the anal verge. Based on the histological features, most anal canal tumors are classified as adenocarcinomas and squamous cell carcinomas [6], although other histological types such as adenosquamous carcinoma, basaloid carcinoma, and malignant melanoma are observed [6]. Anal canal adenocarcinomas are further classified into colorectal, anal gland, and fistula-associated subtypes [6]. Our patient had no history of anal fistula and was diagnosed with adenocarcinoma of anal gland origin.

Treatment of anal canal carcinoma significantly varies according to the histological type. For patients with squamous cell carcinoma without metastasis, combined 5-fluorouracil + mitomycin chemoradiotherapy has been demonstrated to be effective $[7,8]$ and is currently accepted as the standard treatment. Chemoradiotherapy can contribute to the preservation of the anal function and improvement in survival rate. For patients with distant metastasis, combined 5-fluorouracil + cisplatin therapy is recommended [9]. In contrast, no studies have provided convincing evidence for the effectiveness of anal canal adenocarcinoma-specific therapy. The guidelines in Japan and Western countries recommend that patients with anal canal adenocarcinomas should be treated similarly to those with rectal carcinomas because of the similarity in their pathological features $[4,5]$. The patient in the present study was treated according to the guidelines for rectal cancer with distant metastasis. After discussing the treatment plans with the patient, we performed abdominoperineal resection to improve local symptoms (pain, bleeding, and obstruction) before initiating chemotherapy for distant metastases. The chemotherapy regimen was considered based on the treatment guidelines for rectal carcinoma. Treatment options included oxaliplatin-based chemotherapy such as FOLFOX [10], XELOX [10], SOX [11], irinotecan-based chemotherapy such as FOLFIRI [12], IRIS [13], and the combination of molecular targeted drugs. Since the patient had an activating G12D mutation in the KRAS oncogene, anti-EGFR therapy was not an option [14, 15]. After considering the toxicity profiles, administration methods, and patient's compliance, mFOLFOX6 + bevacizumab therapy was chosen. Over approximately 1 year, 22 courses of mFOLFOX6 + bevacizumab therapy were performed. At the time of this report, the patient demonstrated tolerable levels of oxaliplatin-induced peripheral neurotoxicity (grades 1-2). We are going to continue the current treatment unless the patient develops intolerable adverse reactions or progressive disease. In the near future, we plan to conduct imaging stud- 
Matsunaga et al.: Successful Treatment of Metastatic Anal Canal Adenocarcinoma with mFOLFOX6 + Bevacizumab

ies, including PET/CT scan, and consult specialists in respiratory and digestive surgery to determine if operative intervention is appropriate.

In conclusion, we experienced a rare case of anal canal adenocarcinoma with distant metastases, which was successfully treated with mFOLFOX6 + bevacizumab therapy according to the guidelines for rectal carcinoma. Case reports of chemotherapy for anal canal adenocarcinoma with distant metastasis are limited, and there is no convincing evidence for treatment effectiveness. Anal canal carcinoma originates from a wide range of tissues and has multiple histological subtypes. To date, the significance of personalized medicine is widely recognized. We believe that it is important to establish a specific treatment strategy for anal canal carcinoma according to the histological type.

\section{Statement of Ethics}

Informed consent was obtained from the patient for publishing this case and the accompanying images.

\section{Disclosure Statement}

The authors have no conflicts of interest to declare.

\section{References}

1 Siegel R, Naishadham D, Jemal A: Cancer statistics, 2013. CA Cancer J Clin 2013;63:11-30.

2 Multi-Institutional Registry of Large Bowel Cancer in Japan. Japanese Society for Cancer of Colon and Rectum, vol 20. (in Japanese) Cases Treated in 1992. Tokyo, 2000.

-3 Ghosn M, Kourie HR, Abdayem P, Antoun J, Nasr D: Anal cancer treatment: current status and future perspectives. World J Gastroenterol 2015;21:2294-2302.

4 National Comprehensive Cancer Network: NCCN Clinical Practice Guidelines in Oncology. Anal Carcinoma (Version 1, 2016), http://www.nccn.org/professionals/physician_gls/f_guidelines.asp.

5 National Comprehensive Cancer Network: NCCN Clinical Practice Guidelines in Oncology. Rectal Cancer (Version 1, 2016), http://www.nccn.org/professionals/physician_gls/f_guidelines.asp.

6 Japanese Society for Cancer of the Colon and Rectum: Japanese Classification of Colorectal Carcinoma, 2nd English ed. Tokyo, Kanehara \& Co., Ltd., 2009.

7 Nigro ND, Vaitkevicius VK, Considine B Jr: Combined therapy for cancer of the anal canal: a preliminary report. Dis Colon Rectum 1974;17:354-356.

-8 Ajani JA, Winter KA, Gunderson LL, Pedersen J, Benson AB 3rd, Thomas CR Jr, Mayer RJ, Haddock MG, Rich TA, Willett C: Fluorouracil, mitomycin, and radiotherapy vs fluorouracil, cisplatin, and radiotherapy for carcinoma of the anal canal: a randomized controlled trial. JAMA 2008;299:1914-1921.

-9 Faivre C, Rougier P, Ducreux M, Mitry E, Lusinchi A, Lasser P, Elias D, Eschwege F: 5-fluorouracil and cisplatin combination chemotherapy for metastatic squamous-cell anal cancer. Bull Cancer 1999;86:861865.

10 Cassidy J, Clarke S, Diaz-Rubio E, Scheithauer W, Figer A, Wong R, Koski S, Lichinitser M, Yang TS, Rivera F, Couture F, Sirzén F, Saltz L: Randomized phase III study of capecitabine plus oxaliplatin compared with fluorouracil/folinic acid plus oxaliplatin as first-line therapy for metastatic colorectal cancer. J Clin Oncol 2008;26:2006-2012.

11 Yamada Y, Takahari D, Matsumoto H, Baba H, Nakamura M, Yoshida K, Yoshida M, Iwamoto S, Shimada K, Komatsu Y, Sasaki Y, Satoh T, Takahashi K, Mishima H, Muro K, Watanabe M, Sakata Y, Morita S, Shimada Y, Sugihara K: Leucovorin, fluorouracil, and oxaliplatin plus bevacizumab versus S-1 and oxaliplatin plus bevacizumab in patients with metastatic colorectal cancer (SOFT): an open-label, non-inferiority, randomized phase 3 trial. Lancet Oncol 2013;14:1278-1286.

-12 Tournigand C, Andre T, Achille E, Lledo G, Flesh M, Mery-Mignard D, Quinaux E, Couteau C, Buyse M, Ganem G, Landi B, Colin P, Louvet C, de Gramont A: FOLFIRI followed by FOLFOX6 or the reverse sequence in advanced colorectal cancer: a randomized GERCOR study. J Clin Oncol 2004;22:229-237. 


\section{Case Reports in Oncology}

\begin{tabular}{l|l}
\hline Case Rep Oncol 2016;9:249-254 \\
\hline DOI: $10.1159 / 000446107$ & $\begin{array}{l}\text { (c) 2016 The Author(s). Published by S. Karger AG, Basel } \\
\text { www.karger.com/cro }\end{array}$ \\
\hline
\end{tabular}

Matsunaga et al.: Successful Treatment of Metastatic Anal Canal Adenocarcinoma with mFOLFOX6 + Bevacizumab

13 Muro K, Boku N, Shimada Y, Tsuji A, Sameshima S, Baba H, Satoh T, Denda T, Ina K, Nishina T, Yamaguchi K, Takiuchi H, Esaki T, Tokunaga S, Kuwano H, Komatsu Y, Watanabe M, Hyodo I, Morita S, Sugihara K: Irinotecan plus S-1 (IRIS) versus fluorouracil and folinic acid plus irinotecan (FOLFIRI) as second-line chemotherapy for metastatic colorectal cancer: a randomised phase 2/3 non-inferiority study (FIRIS study). Lancet Oncol 2010;11:853-860.

-14 Van Cutsem E, Kohne CH, Hitre E, Zaluski J, Chang Chien CR, Makhson A, D’Haens G, Pintér T, Lim R, Bodoky G, Roh JK, Folprecht G, Ruff P, Stroh C, Tejpar S, Schlichting M, Nippgen J, Rougier P: Cetuximab and chemotherapy as initial treatment for metastatic colorectal cancer. N Engl J Med 2009;360:1408-1417.

15 Douillard JY, Siena S, Cassidy J, Tabernero J, Burkes R, Barugel M, Humblet Y, Bodoky G, Cunningham D, Jassem J, Rivera F, Kocákova I, Ruff P, Błasińska-Morawiec M, Smakal M, Canon JL, Rother M, Oliner KS, Tian Y, Xu F, Sidhu R: Final results from PRIME: randomized phase III study of panitumumab with FOLFOX4 for first-line treatment of metastatic colorectal cancer. Ann Oncol 2014;25:1346-1355.

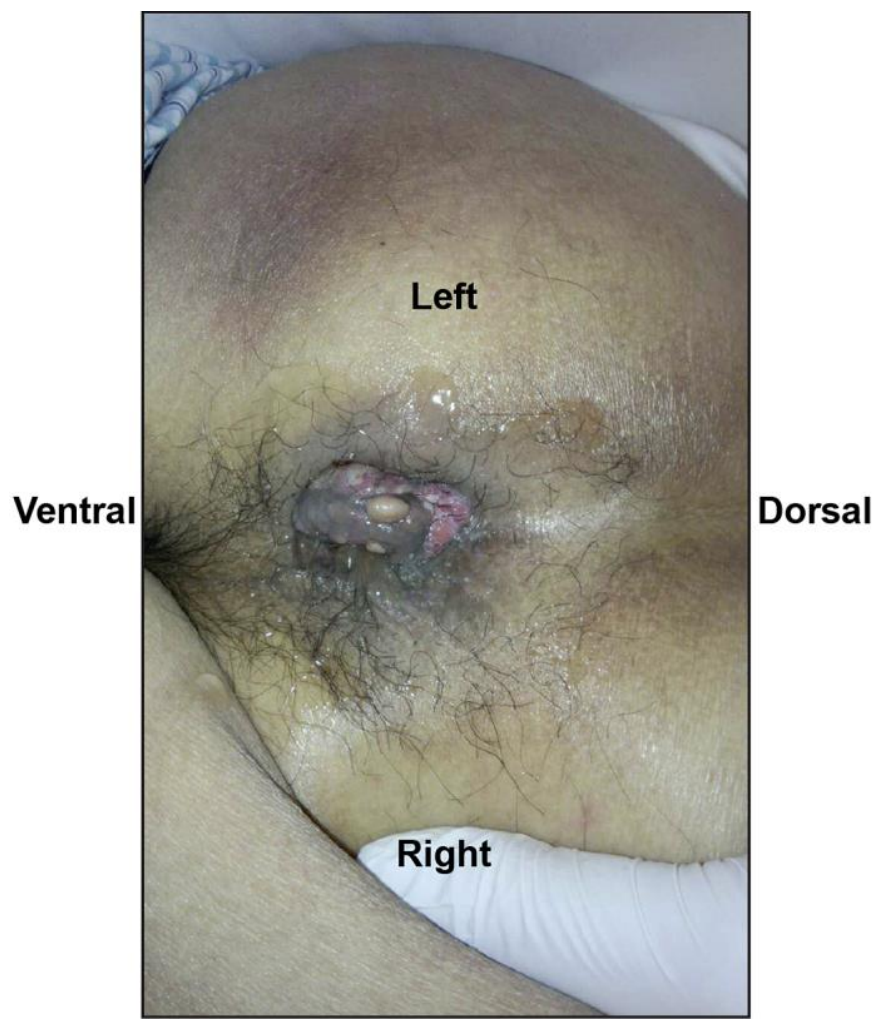

Fig. 1. Visual examination of the anus: a solid mass of a thumb tip size with an uneven indented surface located mainly in the left side of the anus was observed. 


\section{Case Reports in Oncology}
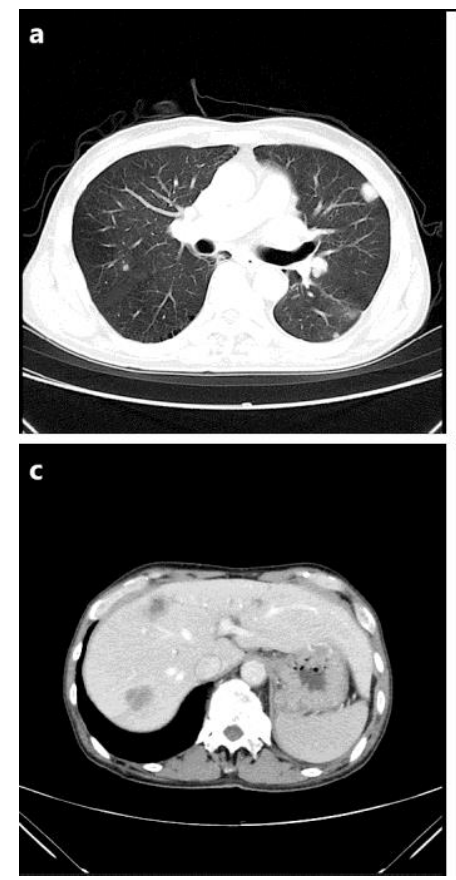

\begin{tabular}{l|l}
\hline Case Rep Oncol 2016;9:249-254 \\
\hline DOI: $10.1159 / 000446107$ & $\begin{array}{l}\text { (c) 2016 The Author(s). Published by S. Karger AG, Basel } \\
\text { www.karger.com/cro }\end{array}$ \\
\hline
\end{tabular}

Matsunaga et al.: Successful Treatment of Metastatic Anal Canal Adenocarcinoma with mFOLFOX6 + Bevacizumab
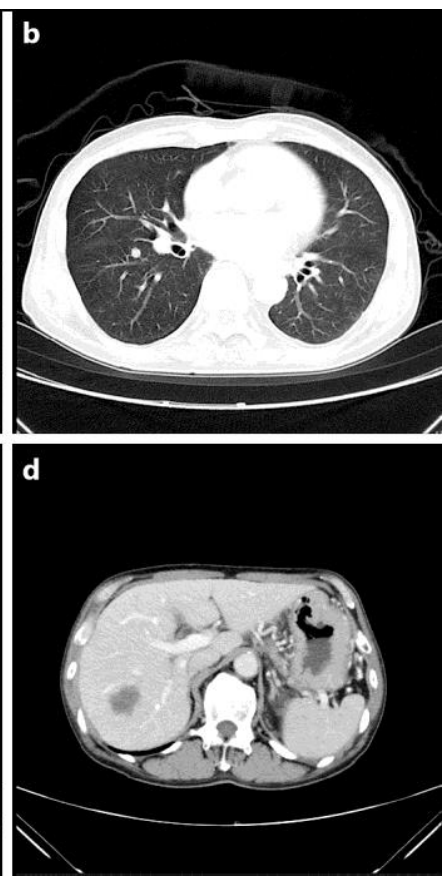

Fig. 2. Thoracic-abdominal CT scan before the start of chemotherapy: multiple metastatic lesions in the lung and liver were detected.
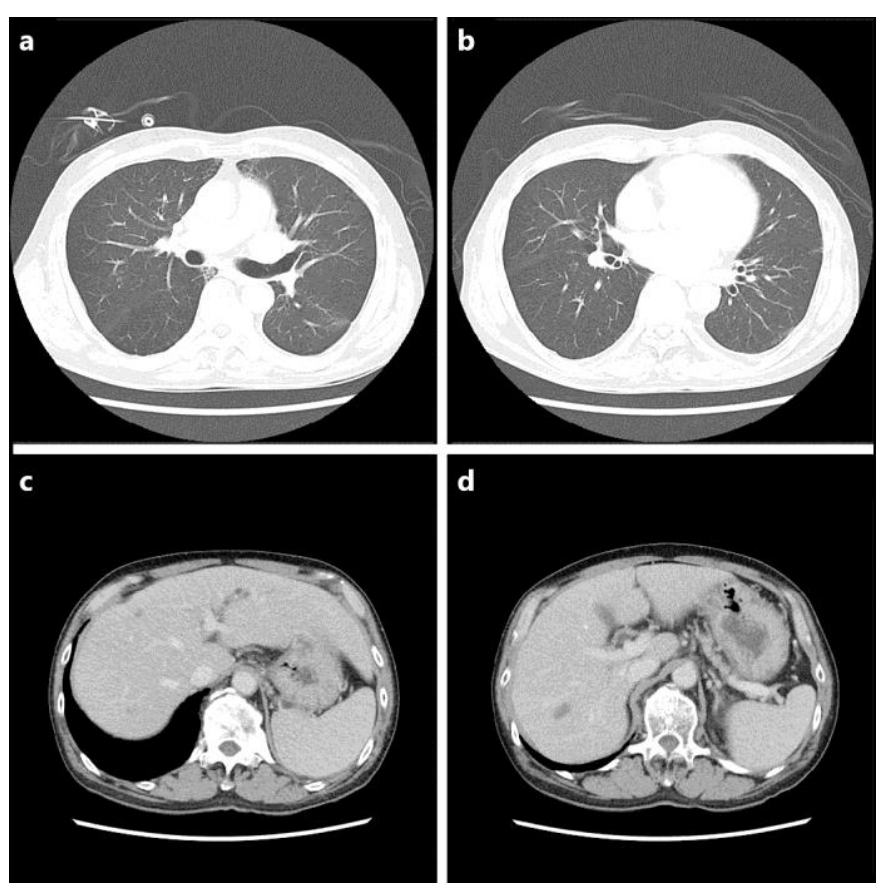

Fig. 3. Thoracic-abdominal CT scan after 22 courses of mFOLFOX6 + bevacizumab therapy: a significant reduction in the size of metastatic lesions in the lung and liver was observed. 